\title{
Design Socialmente Consciente de Jogos: relato de uma oficina prática para o entendimento do problema e prospecção de ideias
}

\author{
Bernardo Ferrari \\ bernaferrari2@gmail.com \\ Universidade Federal do Paraná \\ Curitiba, Brasil
}

\author{
Deógenes P. da Silva Junior \\ deogenesj@gmail.com \\ Universidade Federal do Paraná \\ Curitiba, Brasil
}

\author{
Carolina Moreira Oliveira \\ carolmoliveiraa@gmail.com \\ Universidade Federal do Paraná \\ Curitiba, Brasil
}

\author{
Júlia S. B. Ortiz \\ jubathke@gmail.com \\ Universidade Federal do Paraná \\ Curitiba, Brasil
}

\author{
Roberto Pereira \\ rpereira@inf.ufpr.br \\ Universidade Federal do Paraná \\ Curitiba, Brasil
}

\begin{abstract}
RESUMO
O design de jogos para favorecer comportamentos positivos e saudáveis dos jogadores é tanto uma necessidade quanto um desafio. Embora a área de jogos tenha bastante contribuições na literatura, especialmente no que diz respeito a gamificação, jogos sérios e computação persuasiva, quando o domínio de aplicação é crítico, como educação e saúde, é necessário conduzir práticas que apoiem o entendimento socialmente consciente do contexto no qual o jogo será inserido. Este artigo apresenta uma oficina colaborativa para o entendimento de problema e levantamento de requisitos para um jogo que auxilie crianças a realizar exercícios de fonoaudiologia fora do contexto hospitalar. A oficina foi conduzida para produzir um entendimento sistêmico do domínio do problema, de aspectos humanos e técnicos, das possíveis soluções e suas implicações, utilizados como insumos para a produção do jogo. $\mathrm{O}$ artigo apresenta a oficina e seus principais resultados, discutindo lições aprendidas e a importância de conduzir práticas de entendimento de problema a partir de uma perspectiva sociotécnica antes do desenvolvimento de uma solução e do envolvimento direto do público-alvo.
\end{abstract}

\section{PALAVRAS-CHAVE}

Jogo, Fonoaudiologia, Design Socialmente Consciente

\section{INTRODUÇÃO}

Jogos digitais permeiam a vida humana, não apenas como uma opção de entretenimento, mas como meios de educação, de auxílio em terapia, entre outros. Jogos são elementos que promovem impactos na realidade social. No caso dos jogos sérios (serious games), que vão além do propósito de entretenimento, o processo de construção é complexo, abrangendo diferentes objetivos e desafios dos indivíduos envolvidos, que podem interagir diretamente ou não com o jogo. Especialmente em contextos críticos como a educação, a

Permission to reproduce or distribute, in whole or in part, material extracted from this work, verbatim, adapted or remixed, as well as the creation or production from the content of such work, is granted without fee for non-commercial use, provided that the original work is properly credited.

IHC 2019 - Workshop sobre Interação e Pesquisa de Usuários no Desenvolvimento de Jogos (WIPlay), Outubro 21-25, 2019, Vitória, Brasil. In Anais Estendidos do XVII Simpósio Brasileiro sobre Fatores Humanos em Sistemas Computacionais. Porto Alegre: SBC.

(C) 2019 by the author(s), in accordance with the terms of the Creative Commons Attribution-NonCommercial 4.0 International Public License (CC BY-NC 4.0). segurança ou a saúde, é necessário um entendimento profundo do contexto no qual o jogo será disponibilizado, do impacto esperado com a sua adoção, e dos eventuais problemas e desafios que podem ser desencadeados. Esse entendimento deve ser o ponto de partida para o design do jogo, de modo que ele seja capaz de atender as necessidades das diferentes partes interessadas (stakeholders) envolvidas, sem desencadear efeitos nocivos nas pessoas e no meio em que é utilizado.

O Design Socialmente Consciente [5], pensado para o processo de design de sistemas computacionais de modo geral, tem potencial de contribuir para o design de jogos, pois informa e provoca reflexões sobre o domínio do problema e o potencial de impacto da solução no mundo social. Este Design Socialmente Consciente significa a teoria, artefatos e métodos que precisamos articular para fazer o design socialmente responsável, participativo e universal como processo e produto [5]. Com inspirações no Design Participativo, este modelo de design situa o entendimento de sistemas e o design de tecnologias no nível informal (hábitos, valores, cultura), formal (procedimentos, regras) e técnico (sistema computacional) [5]. Estes diferentes níveis apoiam o design em uma perspectiva sociotécnica: aspectos sociais que influenciam o design da solução técnica e os prováveis impactos que esta solução provoca quando é inserida no mundo social.

O Design Socialmente Consciente é, antes de tudo, uma perspectiva a ser adotada no design de uma tecnologia interativa. De acordo com Piccolo e Pereira [18], essa perspectiva: i) exige a articulação de significados de um grupo social em seus níveis informais e formais para a co-construção do sistema no nível técnico; ii) reconhece o outro e suas diferenças como elementos essenciais para uma visão sistêmica; iii) reconhece a comunicação entre as partes como um fenômeno social culturalmente definido e propõe artefatos para mediar essa comunicação; iv) confia às partes interessadas o poder de projetar e possibilita o seu envolvimento criativo e responsável em soluções de design; v) situa-se em uma realidade socioeconômica e cultural, sem perder sua localização no mundo mais amplo.

O problema explorado neste artigo é o design de um jogo para o contexto de tratamentos de fonoaudiologia. Por ser um tratamento contínuo, o atendimento no contexto hospitalar é apenas uma parte do tratamento, exigindo que exercícios sejam realizados de forma continuada fora do hospital. Quando se trata do público infantil, há dificuldades adicionais para a realização de exercícios de fala em casa, seja por falta de motivação, de disciplina ou até mesmo 
por vergonha, o que pode comprometer os resultados e a evolução da criança com o tratamento. Os jogos têm o potencial de engajar pessoas na execução de tarefas (e.g., exercícios de fala). Entretanto, o design de um jogo para essa finalidade deve ser feito de modo cuidadoso e socialmente consciente. Isso significa que, antes de iniciar o desenvolvimento de qualquer solução, é preciso produzir um entendimento amplo do problema a ser trabalhado, de modo a antecipar requisitos e propor ideias de design que atendam às diferentes partes interessadas envolvidas.

O contexto do problema de fonoaudiologia está associado ao projeto "Sistemas Sócio-Enativos: Investigando Novas Dimensões no Design da Interação Mediada por Tecnologias de Informação e Comunicação" [6], que busca desenvolver o conceito e prática de sistemas computacionais constituídos por processos humanos e tecnológicos, vinculados dinamicamente. No projeto se estabeleceu uma parceria com o Hospital SOBRAPAR ${ }^{1}$ para o design e experimentação de soluções que contribuam com a qualidade de vida das pessoas que frequentam seu ambiente. O desenvolvimento de soluções computacionais no contexto hospitalar deve considerar questões sociais (afetivas, culturais, valores) das pessoas que estão nesse ambiente, considerando aspectos além de utilidade e facilidade de uso [8].

A partir de um estudo etnográfico prévio conduzido no Hospital [8], a área de fonoaudiologia foi identificada como oportunidade para o desenvolvimento e aplicação de soluções computacionais, na qual foi constatado que: i) as atividades realizadas são dependentes da tecnologia para execução do trabalho de forma adequada e eficaz; e ii) a interação médico-paciente ultrapassa o ambiente hospitalar, adentrando o ambiente doméstico por meio de aplicativos (apps) de mensagem disponíveis nos smartphones do paciente e de sua família. Na interação com os profissionais de fonoaudiologia do Hospital foi identificada a oportunidade de design de um jogo para smartphone que auxiliasse os pacientes, em sua maioria crianças, na realização dos exercícios orientados durante a consulta médica.

Assim, considerando o material produzido no estudo etnográfico e no contato com os profissionais de fonoaudiologia do Hospital, uma sessão de design socialmente consciente inspirada nas oficinas de Baranauskas [7] foi conduzida com especialistas em Interação Humano-Computador (IHC), todos com formação superior, para propor uma solução que deveria ser construída e avaliada antes de apresentar qualquer ideia ou produto ao Hospital.

As atividades realizadas na oficina de design foram de entendimento de problema e ideação de uma solução, envolvendo a perspectiva de diferentes partes interessadas nos níveis informal, formal e técnico. Para a realização da oficina foram utilizados artefatos inspirados na Semiótica Organizacional e no Design Participativo, como o Diagrama de Partes Interessadas (DPI), o Quadro de Avaliação e a Escada Semiótica. Para a ideação colaborativa foi utilizado o Quadro de Prospecção de Valor e a técnica Brainwriting.

Ao final da oficina, os artefatos sobre o domínio do problema foram preenchidos (DPI, Quadro de Avaliação e Escada Semiótica), assim como ideias e elementos de um jogo foram produzidos colaborativamente tendo como foco os benefícios que ele deveria trazer para duas partes interessadas principais: a criança e a fonoaudióloga O jogo foi proposto para ser dividido em módulos com diversos

\footnotetext{
${ }^{1}$ http://www.sobrapar.org.br/
}

desafios e elementos para promover engajamento e colaboração na realização dos exercícios.

\section{CONTEXTO DO PROBLEMA}

Como ponto de partida para a oficina foi realizada uma apresentação sobre o contexto do problema, elaborada com base nos resultados do estudo etnográfico conduzido no Hospital. Os problemas de voz e fala podem afetar a comunicação, a vida social e influenciar em problemas psicológicos e emocionais [12]. Como a Fonoaudiologia, é diverso o campo de terapia de fala e linguagem. Neste campo, são tratados em adultos e crianças os problemas de fala e linguagem que podem ter sido causados por diferentes condições, como doenças, deficiências, ferimentos, entre outros [11].

Cerca de $10 \%$ das crianças entre 4 e 7 anos possuem algum distúrbio de voz e fala [20]. Esses problemas variam em grau, sendo mais severos em crianças com deformidades craniofaciais. A assistência dos profissionais é necessária para promover o desenvolvimento correto da fala, ou em alguns casos, para retornar a habilidade de falar corretamente [11]. Este trabalho de fonoaudiologia é uma das atuações que ocorrem no Hospital SOBRAPAR.

O Hospital SOBRAPAR é uma instituição filantrópica que oferece tratamento cirúrgico e reabilitação de pacientes com deformidades craniofaciais congênitas ou adquiridas. Os pacientes recebem atendimento a cada quinze dias de forma gratuita pelo Sistema Único de Saúde (SUS), no qual ocorre acompanhamento do tratamento. De modo geral, além do atendimento no Hospital, os profissionais de fonoaudiologia requerem que seus pacientes realizem exercícios em casa, de preferência sete dias por semana.

Há desafios do Hospital no contexto fonoaudiológico, como o prolongamento do tratamento e aumento de custo caso os exercícios não sejam realizados em domicílio, prejudicando os benefícios esperados. Outro desafio é o acesso e o comparecimento nos atendimentos presenciais, pois muitos pacientes vivem em localidades distantes do Hospital e precisam se deslocar por grandes distâncias (dezenas ou centenas de quilômetros) para a consulta. Ainda existe uma certa resistência por parte dos pacientes, em sua maioria crianças, de comparecer à consulta.

A realização de exercícios de fonoaudiologia em casa é importante e deve ser efetiva e útil aos envolvidos, como a fonoaudióloga, a criança e sua família. O Hospital demanda meios de promover o engajamento no tratamento, no qual uma solução deve ser concebida de modo que faça sentido para o contexto do hospital e seu público, contribuindo com as partes interessadas envolvidas.

\subsection{Desenvolvimento de Jogos e o Design Socialmente Consciente}

Brincar é um elemento sedutor à criança, e com seu manejo o adulto (e.g., fonoaudióloga) desperta na criança o interesse e a conduz à novas aquisições [19]. O atendimento e tratamento com a criança pode seguir um viés lúdico, contribuindo para o interesse e empenho dela nas atividades propostas. Uma forma de brincar é por meio de jogos, os quais podem ser utilizados por fonoaudiólogos, pais e professores como instrumentos de ensino que facilitem atividades perceptivas, auditivas e visuais, entre outras [19].

Os jogos podem possuir objetivos além de apenas entretenimento, como é o caso dos jogos educacionais ou sérios. Jogos educacionais 
são aqueles criados para ensinar ao mesmo tempo que entretém [15], enquanto os jogos sérios consideram os mesmos objetivos de educação e entretenimento, mas incluem todos os aspectos da educação: ensino, treinamento e informação [14]. Da mesma forma que jogos sérios devem auxiliar os professores, e não os substituir [14], é esperado que um jogo com finalidade terapêutica não substitua o profissional, mas o apoie em suas atividades. O fonoaudiólogo utiliza da brincadeira ou do jogo pois dali surge uma produção de linguagem, que é suscetível a sua análise, assim como o brincar também é uma atividade que coloca em funcionamento a fala da criança [19]. O jogo estimula a realização das atividades de fonoaudiologia em contextos além dos hospitalares, sendo que o jogo é um ambiente que encoraja a aprendizagem ativa [15], por exemplo ao permitir que a criança tenha um feedback e aprenda sobre sua fala, ao mesmo tempo que informa dados importantes para o profissional de fonoaudiologia que a esta acompanhando.

A construção de jogos que atuem em um cenário delicado e complexo como o de problemas de fonoaudiologia é um desafio tanto no aspecto de apoio à terapia quanto no aspecto educacional e terapêutico. No contexto de fonoaudiologia, não se trata apenas de desenvolver um jogo de entretenimento. Toolkits e abordagens existentes para desenvolvimento de jogos de lazer e entretenimento não podem simplesmente ser transferidas para a educação ou para a saúde, por causa de suas diferentes características [23]. Um jogo para apoiar o contexto citado neste trabalho também possui complexidade adicional ao relacionar educação, tratamento médico e um público desafiador (i.e., o público infantil) em condições socioeconômicas igualmente desafiadoras.

Com o propósito de conhecer quais são as opções existentes para o problema de fonoaudiologia, seus aspectos positivos e oportunidades de soluções, foi realizada uma busca nas lojas digitais Play Store e App Store, entre agosto e setembro de 2018, por aplicativos (apps) que se enquadram no contexto de fonoaudiologia. A busca foi realizada com os seguintes termos relacionados ao contexto de fonoaudiologia: "fonoaudiologia", "audiologia”, "disfagia”, "terapia de fala", "speech therapy" e "articulation". Os resultados das buscas foram ordenados por relevância e como critério foram selecionados os primeiros 40 resultados de cada pesquisa que estavam relacionados ao tratamento fonoaudiológico para crianças. Considerou-se este número de resultados como apropriado para atingir um conjunto representativo de apps relacionados ao tema proposto. Ao final do processo, foram retornados 240 resultados - não foram retirados os apps duplicados desse número (duplicados entre as diferentes buscas e entre as bibliotecas Play Store e App Store).

Dentre os apps foram identificados três grupos distintos:

- jogos que dependem de uma pessoa externa para garantir a pontuação adequada;

- jogos que apresentam a imagem de um objeto, ou pronuncia palavras e aguarda a identificação das sílabas pelo usuário;

- jogos movidos pelo som que a pessoa emite;

Existe uma distinção entre: i) soluções que foram projetadas para profissionais da área usarem com pacientes e ii) soluções que foram feitas especificamente para crianças. Os jogos projetados para profissionais muitas vezes necessitam de cadastro, internet, possuem uma interface carregada em texto, e uma disposição dos menus ou opções que não é fácil de entender. Os jogos projetados para crianças são o oposto: pontuação objetiva, fáceis de aprender e usar, com menus grandes, coloridos e auxiliados por ícones de modo que muitas vezes não necessitam de leitura. Dentre os apps analisados, os que mais se encaixam no escopo deste trabalho foram o Fofuuu [10] e Amigofono [2], que possuem custo elevado, por volta de 200 a 700 reais por ano, variando o preço de acordo com número de pacientes e tamanho da biblioteca de exercícios. Apenas o app pago Fofuu [10] faz uso da voz como entrada no jogo.

O Fofuuu contém 10 jogos com dezenas de fases ao total, que podem ser aplicadas em vários fonemas diferentes. Em teste realizado neste app foram identificados problemas que podem ocasionar dificuldades para os jogadores. Por exemplo, o reconhecedor de fala apresenta erros na precisão de acerto de falas: em uma das partidas realizadas, o som que o próprio jogo emitia era entendido como a voz do usuário, fazendo com que movimentos fossem registrados involuntariamente, ou que a pontuação fosse emitida mesmo com o jogador em silêncio. A interface do jogo é difícil de utilizar, com elementos pequenos e erros na mudança de orientação do celular. Deste modo, por diversos motivos os apps identificados não atendem ao contexto trabalhado.

Uma variedade de métodos e frameworks têm sido propostos para jogos sérios ou educacionais. Westera et al. [23] apresentam um framework conceitual para desenvolvimento de jogos sérios do gênero de cenários e narrativas. $\mathrm{O}$ framework assume para o ambiente do jogo educacional quatro mundos (ou subsistemas): gameplay, aprendizagem, professor e gerenciamento. Apesar de apresentar mundos relevantes para um jogo sério, o framework foca em um tipo específico de jogo, que envolve principalmente a atividade de leitura, que não é tão acessível ou atraente para o público infantil.

Para o design de jogos sérios de forma geral, Yusoff et al. [24] apresentam um framework conceitual composto de habilidades e conceitos educacionais em conjunto com elementos de jogos (e.g., gênero, mecânica). Entretanto, o framework apoia apenas o desenvolvimento de objetivos educacionais e técnicos para o jogo. No contexto apresentado neste artigo, há uma necessidade anterior ao estabelecimento de objetivos terapêuticos ou educacionais e da implementação técnica do jogo. Neste caso, o problema de fonoaudiologia lida com um cenário em que é necessário conhecer as partes interessadas e seus contextos socioculturais, o contexto hospitalar, a atuação profissional e as questões médicas subjacentes.

Para o design de jogos em uma perspectiva sociotécnica, Cardoso et al. [9] propõem a ferramenta conceitual E-MUnDI, que oferece uma estrutura para a análise de elementos de Usuário, Implementação e Universo Diegético de um jogo, fundamentada em blocos básicos de cultura. Embora a E-MUnDi possua uma abordagem informada culturalmente, ela foca principalmente nos aspectos do design e implementação dos jogos em si, sem considerar explicitamente elementos de fora do jogo, como informações do contexto social (onde e por quem os jogos serão jogados). Para um jogo sério, educacional e terapêutico, há requisitos e um problema anterior ao jogo, que não é de todo considerado na E-MUnDi, apenas parcialmente no nível de Usuário.

Nesta motivação, o Design Socialmente Consciente e os artefatos da Semiótica Organizacional foram aplicados como apoio à concepção de um jogo em uma oficina de design. A Semiótica 
Organizacional apresenta as teorias e métodos que permitem a análise e design em termos de expressão de significados, comunicação de intenções e criação de conhecimento, considerando aspectos semióticos da interação humana em uma organização [21].

A partir do Design Socialmente Consciente, o propósito foi produzir um entendimento contextualizado e sistêmico do domínio do problema e da subsequente proposta de solução de forma colaborativa entre diferentes participantes, antes de apresentar soluções para o hospital e antes do contato direto com o público-alvo. Essa abordagem foi adotada pois possibilita um entendimento mais abrangente sobre as partes interessadas do problema, assim como uma visão que considera diversos aspectos da provável solução, desde os sociais até os técnicos.

\section{OFICINA DE DESIGN}

A oficina ocorreu em novembro de 2018, com duração de 4 horas e 20 minutos. Participaram das atividades da oficina 10 pessoas: um estudante de graduação em Ciência da Computação, quatro estudantes de mestrado em Informática, um mestre em Engenharia Elétrica e Informática Industrial, três estudantes de doutorado em Computação e um doutor na área de IHC. Como materiais, foram utilizados papéis em branco, post-its, canetas e banners de lona com representações impressas dos artefatos de DPI, Quadro de Avaliação e Escada Semiótica.

A oficina foi dividida nas etapas de entendimento de problema e de ideação, ambas de forma colaborativa. As atividades realizadas são apresentadas na Figura 1, sendo o preenchimento dos artefatos de: DPI, Quadro de Avaliação, Quadro de Prospecção de Valor, Escada Semiótica e Brainwriting Colaborativo.

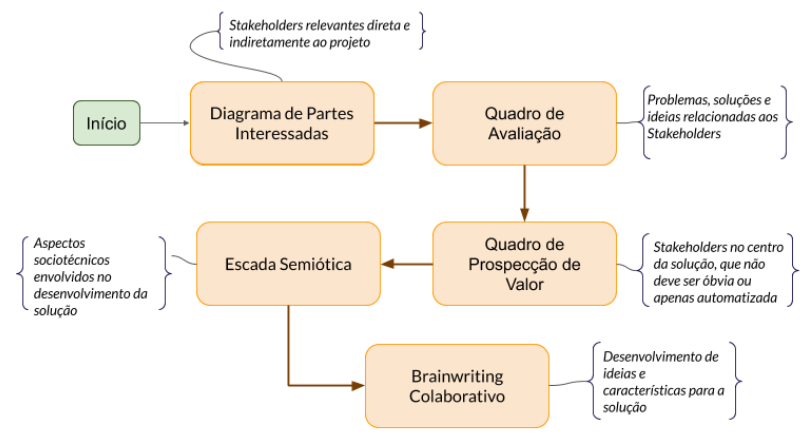

Figura 1: Atividades desenvolvidas na oficina de Design Socialmente Consciente.

A oficina teve início com uma apresentação e discussão sobre as bases conceituais que fundamentam as práticas que seriam conduzidas, como o Design Socialmente Consciente, a Semiótica Organizacional, e os artefatos selecionados, como o DPI. Esta etapa teve duração de 1 hora e 10 minutos. Como parte dos participantes não tinha conhecimento ou domínio sobre os artefatos e a Semiótica Organizacional, este primeiro momento foi relevante para estabelecer as bases de trabalho ao mesmo tempo que provia um treinamento sobre os conceitos que seriam abordados na sequência.
Com o entendimento dos conceitos e artefatos a serem utilizados, foi iniciada a apresentação do contexto do Hospital parceiro, a temática já adotada em outras iniciativas (animais com narrativas, como o macaco Chico), as necessidades de fonoaudiologia e soluções existentes. Esta apresentação durou cerca de 30 minutos e considerou: i) requisitos preliminares para uma solução computacional advindos de estudos etnográficos no Hospital; ii) temática de animais físicos e virtuais que habitam o Hospital e já desenvolvida pela equipe do Projeto com o SOBRAPAR; iii) funcionalidades de apps existentes na Google Play e App Store para o problema de fonoaudiologia.

O preenchimento dos artefatos de maneira colaborativa iniciou a partir do DPI, mapeando e verificando as partes interessadas que influenciavam ou eram influenciadas pelo projeto da solução computacional. Esta etapa durou cerca de 20 minutos. O objetivo da identificação de partes interessadas é clarificar o problema e compartilhar conhecimento, determinando de forma abrangente o escopo de partes direta ou indiretamente envolvidas no problema e no impacto de uma solução. $\mathrm{O}$ artefato distribui as partes interessadas em categorias diferentes que representam forças de informação distintas em relação ao problema em análise (categoria chamada de Operação) [7]. São categorias de partes interessadas do DPI:

- atores e responsáveis (contribuição): aqueles que contribuem diretamente para o problema ou sua solução e/ou são afetados de modo direto por ele.

- clientes e fornecedores (fonte): aqueles que fornecem dados e/ou são fonte de informações para o problema ou sua solução, ou fazem uso deles.

- parceiros e concorrentes (mercado): aspectos de mercado relacionados ao problema.

- espectador e legislador (comunidade): representantes da comunidade que influenciam e são influenciados pelo problema no contexto social.

Com as partes interessadas identificadas foi realizado o preenchimento do Quadro de Avaliação, que estende o DPI e prospecta sobre atuais ou prováveis problemas das partes interessadas. Esta etapa durou cerca de 40 minutos. $\mathrm{O}$ artefato possui um campo para identificação de ideias ou soluções vislumbradas que possuem potencial impacto no desenho da solução para o problema [7]. Para cada categoria de parte interessada, tem-se uma análise de problemas relacionados e ideias para solução. O propósito é antecipar os problemas que cada parte interessada poderia trazer para o contexto do design, assim como as possíveis ideias de soluções.

A partir dos problemas e soluções relacionadas a diversas partes interessadas, o Quadro de Prospecção de Valor foi utilizado, no qual o propósito foi verificar quem são, dentre as identificadas no DPI, as partes interessadas centrais para a solução que a equipe projetará. Esta etapa durou cerca de 20 minutos. Para estas partes interessadas, é mandatório identificar suas reais necessidades, dificuldades, medos e desafios, especialmente identificando como uma solução computacional poderia melhorar a vida dessas partes interessadas. A solução deve ser inovadora, indo além da especificação de uma solução comum, e surpreender as partes interessadas de forma positiva. O Quadro possui cinco campos: (1) Stakeholder Central, que é base para o preenchimento dos outros campos; os campos (2) O que essas pessoas realmente precisam e (3) Quais dificuldades essas pessoas enfrentam, que se referem ao contexto do domínio do 
problema e das necessidades das partes interessadas priorizadas; e os campos (4) Em quais aspectos a solução pode melhorar a vida dessas pessoas? e (5) Como a solução pode surpreender e inovar? que se referem ao contexto da solução e buscam verificar aspectos para ampliar seu valor para a vida das partes interessadas.

Após a identificação das principais partes interessadas, de suas demandas e desafios para o contexto de design, o preenchimento da Escada Semiótica foi iniciado para identificar requisitos para a solução a ser concebida, considerando desde requisitos de infraestrutura técnica até requisitos do ambiente de uso e seus possíveis impactos nas partes interessadas. Esta etapa durou cerca de 30 minutos. A Escada Semiótica possui seis degraus, ou camadas, conforme nome e descrição apresentados a seguir:

(1) Mundo Social: consequência dos usos de signos nas atividades humanas; lida com crenças, expectativas etc.

(2) Pragmática: estuda o uso intencional de signos e o comportamento de seus agentes.

(3) Semântica: trata das relações entre um signo e aquilo a que se refere.

(4) Sintática: trata da combinação de signos sem considerar sua significação específica.

(5) Empírico: lida com as propriedades estáticas dos signos, quando mídias e dispositivos físicos diferentes são usados.

(6) Mundo Físico: trabalha com os aspectos físicos dos signos e suas marcas.

Os três degraus superiores da escada são relacionados ao sistema de informação humano, no uso de signos, como eles funcionam na comunicação de significados e intenções, e quais são as consequências sociais de seu emprego. Os três degraus inferiores consideram aspectos de infraestrutura tecnológica, respondendo questões relacionadas a como os signos são estruturados e usados na linguagem, como são organizados e veiculados, que propriedades físicas possuem, etc [13].

Com os participantes tendo uma noção mais clara dos propósitos da solução a ser projetada, foi utilizada a técnica de Brainwriting, para descrever temas para a solução e como esta devia operar. Esta etapa durou cerca de 50 minutos. A técnica de Brainwriting se refere a geração de ideias de forma escrita por um grupo de pessoas [22]

Na técnica de Brainwriting, cada participante recebe um papel para escrever suas ideias e, depois de certo tempo, a escrita é interrompida e os papéis são passados entre os participantes do grupo, que continuam a escrita adicionando novas ideias ou alterandoas com base nas ideias escritas pelos outros participantes. Essa atividade é repetida até que todos possam ter contribuído com a escrita dos demais participantes. O propósito de utilizar a técnica de Brainwriting é para que todos os envolvidos possam contribuir com o desenvolvimento de uma solução. Ao final da oficina, tem-se produções realizadas colaborativamente, em que o objeto final foi concebido por meio da ação de todos. Nesse caso, foram propostas ideias sobre como deveria ser a solução a ser construída, bem como temas para a interação com o jogo e para a história. Houve um momento de socialização e consolidação dos resultados e as produções foram entregues ao projetista para usar como inspiração na construção do jogo. Após o fim da atividade de Brainwriting os agradecimentos foram realizados e a sessão foi encerrada.

\section{RESULTADOS}

Esta seção apresenta os resultados da oficina de design realizada, sendo a compreensão do domínio do problema a partir do preenchimento dos artefatos da Semiótica Organizacional e a caracterização do jogo produzido.

\subsection{Preenchimento dos Artefatos}

No DPI foram identificadas 21 partes interessadas que influenciam ou poderiam ser influenciadas pela solução. A Figura 2 apresenta as partes interessadas divididas entre as categorias. É possível que uma parte interessada pertença a mais de uma categoria ao mesmo tempo, por exemplo: "Profissionais do Hospital", "Fonoaudióloga" e "Crianças" pertencem ao mesmo tempo das categorias Contribuição e Fonte.

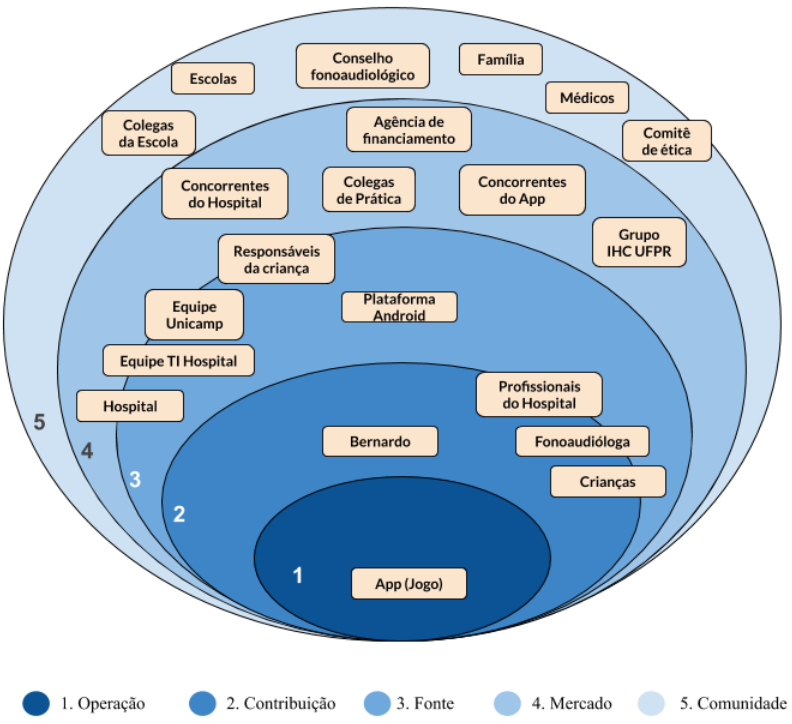

Figura 2: Diagrama de Partes Interessadas preenchido.

Dada a quantidade de partes interessadas identificadas, verificamos a abrangência que o diagrama possibilita no entendimento do domínio do problema. As partes interessadas identificadas vão além das óbvias, como a criança e a fonoaudióloga, permitindo identificar inclusive as que, embora não fossem usuárias diretas da solução, eram cruciais para promover ou viabilizar o seu uso. De modo geral, foram identificadas:

- na implementação da solução: Bernardo, grupo IHC-UFPR, equipe Unicamp, equipe TI Hospital;

- no atendimento fonoaudiológico: criança, fonoaudióloga, profissionais do hospital, responsáveis pela criança, médicos, colegas de prática;

- no cotidiano da criança: escolas, colegas de escola, família;

- demais partes interessadas: conselho fonoaudiológico, comitê de ética, concorrentes do $a p p$, agência de financiamento, concorrentes do hospital;

Deste modo, identificamos possíveis parceiros e concorrentes ao sucesso da solução, como os concorrentes do app e do Hospital, e partes interessadas que regulamentam sobre a possível utilização 
da solução, como o conselho fonoaudiológico e comitê de ética. As partes interessadas do cotidiano da criança nos informam possíveis usuários da solução que também podem ser beneficiados ou, pelo menos, podem influenciar no uso da mesma pela criança. As partes interessadas envolvidas no atendimento fonoaudiológico podem ser consultadas ou envolvidas diretamente na concepção ou avaliação da solução, pois possuem visões próprias sobre o problema ao vivenciá-lo cada um da sua maneira.

A partir do DPI, verificamos no contexto de fonoaudiologia que as crianças podem eventualmente realizar as atividades em diferentes contextos, como em seu próprio domicílio, ou na casa de parentes, na escola e no próprio Hospital. Enquanto estão nestes contextos, outras pessoas podem fazer parte da realização dos exercícios, criando experiências colaborativas que ajudam a criança internalizar o aspecto lúdico e a importância dos exercícios. O jogo, ao possibilitar uma interação com diversas pessoas, também contribui para a redução de possíveis receios ou angústias da criança por ter que realizar exercícios que seus colegas ou familiares não realizam, contribuindo para reduzir sentimentos como vergonha $\mathrm{e}$ medo.

Após a identificação das partes interessadas, avançamos para o preenchimento do Quadro de Avaliação com os stakeholders identificados, seus respectivos problemas e soluções. Pelo motivo de tempo disponível, nem todas as partes interessadas foram verificadas no Quadro de Avaliação. Entretanto, seguindo a recomendação da literatura [17], garantimos que ao menos uma parte interessada de cada categoria do DPI tivesse sido representada no Quadro de Avaliação. Deste modo, buscamos a abrangência da análise ao considerar partes interessadas com diferentes níveis de influência no projeto da solução.

No Quadro de Avaliação, verificamos desafios e requisitos que nos informam diretamente sobre como a solução deve ser e operar. Por exemplo, a importância de aspectos de praticidade, motivação, personalização, interesse e infraestrutura técnica, como a sincronização e o recurso de internet. Verificamos informações relacionadas ao contexto social do problema, por exemplo: muitas famílias não possuírem internet, o que implica na solução não depender somente de conexão para funcionar e nem consumir dados móveis. Outro aspecto do contexto social do problema foi que a família pode ser heterogênea e pode variar quem acompanha a criança em seu dia a dia e nos atendimentos ao hospital. Essas pessoas podem ser aliadas, beneficiadoras ou prejudiciais à solução. Algumas premissas em relação ao problema foram tomadas:

- nem toda família possui recursos técnicos para utilizar a solução, como smartphone e acesso à internet;

- a criança pode não possuir um dispositivo único e pessoal para utilizar a solução;

- não se trata apenas de resolução de exercícios fonoaudiológicos, mas de uma atividade que envolve outros aspectos, como:

- o uso do celular ou de outro dispositivo móvel;

- a concorrência com outros afazeres, apps ou jogos;

- a falta de tempo, apoio ou engajamento para realização das atividades;

- o constrangimento em realizar atividades que envolvem a fala;
- um possível motivo de deboche por familiares, colegas de escola ou outro grupo social pela criança realizar determinadas atividades de fala.

Ao partir para o Quadro de Prospecção de Valor, foram identificados diversos elementos (representados na Figura 3) para as partes interessadas principais da solução: Criança/Paciente e Fonoaudióloga. Embora todas as partes interessadas sejam relevantes para a solução, o motivo da prioridade maior para o paciente foi o fato de que é ele quem deverá usar o app diariamente e ter o maior benefício com seu uso. A importância da fonoaudióloga pode ser justificada pois é a profissional que já trabalha com esse propósito de melhoria de fala com a criança e quem indica exercícios para serem realizados em casa. Em projetos centrados no usuário, é comum que o usuário, que espera obter o principal benefício com a solução, seja deixado de lado e não seja considerado realmente central. Em seu artigo Reimagining HCI, Bannon [4] chama a atenção para diferentes contextos, como o de Ambient Assisted Living, nos quais soluções são desenvolvidas sob a justificativa de melhorar a qualidade de vida das pessoas em casa em invés de permanecerem em hospitais ou instituições. Entretanto, ao examinar cuidadosamente, é comum que essas soluções acabem se preocupando em oferecer monitoramento 24 horas por dia e sete dias por semana, sem se preocupar explicitamente em melhorar a qualidade de vida das pessoas, promovendo sua autonomia e valores. Isso tende a ocorrer quando a parte interessada principal é deixada fora do foco e do ponto de partida ao se entender o problema e conceber uma solução.

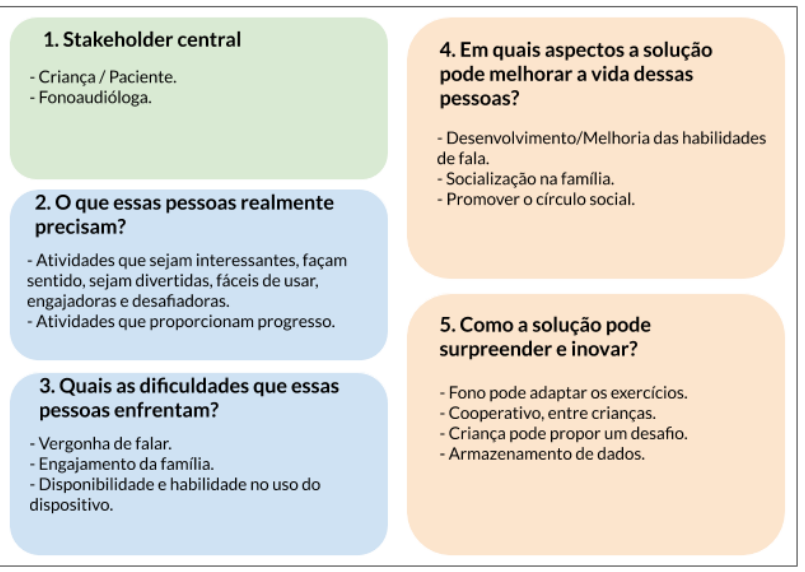

Figura 3: Quadro de Prospecção de Valor preenchido.

No Quadro de Prospecção de Valor, questionamos nossos conhecimentos sobre o domínio do problema que talvez já estejam fixos, especialmente no que diz respeito às partes interessadas centrais. Ao questionar sobre o quê as partes interessadas realmente precisam, deixamos explícito que a criança precisa de atividades que proporcionem principalmente diversão e progresso em seu tratamento e aprendizagem. Para manter o engajamento e a utilização da solução pela criança, as atividades devem fazer sentido e serem interessantes, divertidas, engajadoras, desafiadoras e fáceis de aprender a usar. 
Com uma dinâmica de jogo baseada em voz, é possível que algumas crianças tenham vergonha de falar, o que pode prejudicar a realização de atividades orais. Além disso pode ocorrer da família não incentivar ou não se engajar no tratamento. Há a possibilidade, por exemplo, da família só possuir um aparelho celular e a criança querer utilizá-lo enquanto outra pessoa também precisa. Assim, se por um lado a disponibilidade do dispositivo pode ser um ponto desafiador dependendo da família, por outro é um problema contornável pelo hospital e parceiros, por exemplo: se a solução for capaz de operar em um dispositivo de baixo custo, ela poderia operar em um dispositivo oferecido pelo hospital.

Uma solução de baixo custo baseada em jogos, que exercita a fala como comando para a jogabilidade, pode contribuir com a melhoria das habilidades de fala da criança, influenciando em maior confiança e desenvolvimento de habilidades sociais. Tal solução também pode auxiliar no engajamento e interação com a família se as atividades de exercício de fala forem colaborativas e convidarem a participação de diversas pessoas do grupo social da criança.

Do ponto de vista terapêutico, a solução pode surpreender e inovar ao permitir que os profissionais de fonoaudiologia possam propor as atividades como desejarem, promovendo uma personalização de atividades para cada realidade e características individuais de determinada criança. A solução também pode inovar oferecendo recursos para análise do progresso continuado do tratamento, especialmente no tempo decorrido até a próxima consulta. Outro aspecto de inovação é a possibilidade da criança propor desafios no jogo, assim como o jogo promover funcionalidades cooperativas entre as crianças, crescendo um senso de auxílio, divertimento e aprendizagem mútuas. A ideia de armazenar os dados no celular e transferir quando o dispositivo estiver conectado na Wi-Fi do hospital é algo que nenhuma outra solução encontrada para o domínio do problema faz, e que permite ao profissional de saúde obter dados sobre o progresso do tratamento sem onerar o paciente com a transmissão de dados.

A inovação e a surpresa são elementos relevantes, por exemplo, para promover o engajamento com o jogo, para que favoreça um sentimento de clímax, ou para que chame atenção de jogadores. Estes elementos podem ser os principais atrativos em uma solução e podem impactar em aspectos de implementação e conteúdo do jogo, como sua jogabilidade, enredo e estética. Estes diversos aspectos foram explorados ainda com os degraus da Escada Semiótica.

No degrau físico ocorrem discussões e definições de projeto, como o sistema operacional Android, que é o sistema operacional presente na maior parte dos celulares da população brasileira, principalmente nos celulares mais acessíveis à população socioeconomicamente vulnerável. A solução também deveria funcionar em um celular ou outro dispositivo móvel, pois: i) permite a captura de voz com maior facilidade pelo microfone embutido; ii) nas famílias um celular pode ser mais presente que um computador; e iii) possibilita a mobilidade entre diferentes contextos, como a casa e o hospital.

No degrau empírico, verificamos que as famílias não possuem disponibilidade de internet banda larga, muitas delas utilizando somente conexão de dados móveis ou a conexão Wi-Fi no próprio Hospital. A solução também não deveria requerer muito de armazenamento do celular, pois os celulares das famílias poderiam possuir pouco espaço de armazenamento disponível tanto pelos dispositivos terem capacidade limitada quanto pelo celular já armazenar outras informações, como fotos, mensagens, apps, entre outros. Deste modo, foi identificada a possibilidade de utilizar serviços de nuvem para armazenamento dos áudios e outras informações, que seriam sincronizadas quando o celular estivesse conectado a uma rede $\mathrm{Wi}-\mathrm{Fi}$, como acontece quando a família vai ao Hospital para acompanhamento médico.

No degrau sintático, verificamos a opção de utilizar o padrão de interface Material Design, por ser um modelo gráfico robusto, sendo utilizado nos produtos Google. Além disso, verificamos a possibilidade de utilizar o padrão e ideias do Projeto já em desenvolvimento que adota uma temática baseada em animaizinhos que habitam o Hospital [8].

No degrau semântico, discutimos o significado dos exercícios e das funcionalidades oferecidas aos usuários e interessados na solução. Essa significação das funcionalidades deve ser bem estabelecida para evitar provocar constrangimento aos usuários e auxiliá-los a atingir seus objetivos, como atingir os benefícios que a solução se propôs a alcançar.

No degrau da pragmática, elencamos os aspectos que a solução quer explicitamente promover, como o engajamento, a visibilidade, a socialização e a execução dos exercícios fora do ambiente hospitalar. Para isso, algumas opções de conteúdo foram propostas, como utilizar da temática já adotada em outros projetos no Hospital, mantendo coerência e promovendo o engajamento com e a partir de outros projetos. Também foi verificada a possibilidade de utilizar a temática de um vilão no jogo, que promoveria a exclusão de outros animais em seu cotidiano.

Com a definição da ideia geral da solução, o conhecimento representado e levantado colaborativamente entre os participantes foi desenvolvido a partir da técnica de Brainwriting para gerar ideias sobre o estilo e temática do jogo. De modo geral, pontos em comum foram encontrados nas produções escritas, descritos a seguir:

- temática de animais (inspirada na temática já adotada no hospital);

- habilidades personalizadas/únicas para animais diferentes;

- permitir selecionar o gênero dos personagens;

- sons específicos para animais específicos (e.g., "au” para cão);

- diversos cenários e temáticas (deserto, floresta, hospital);

- dinâmica envolvendo um ambiente físico, por exemplo palavras (em papel) escondidas no prédio do Hospital que devem ser pronunciadas no app;

- possuir chefões e algumas fases mais difíceis (e.g., super sílabas);

- várias opções ou modalidades de jogos para não ser repetitivo para criança;

- possibilidade do progresso no jogo alimentar um Pet, deixá-lo feliz, etc;

- possibilidade da criança interagir com outras crianças;

- possibilidade da fonoaudióloga customizar exercícios e atividades;

- possibilidade da fonoaudióloga acompanhar a evolução na realização dos exercícios e atividades.

Também foram identificadas nas produções dos participantes ideias inspiradas em jogos existentes, no estilo do jogo WarioWare, 
com sons; Frogger infinito com a voz (estilo Cross Road); Flappy Bird com sons; Futebol (fala para aumentar força, chutar ao gol); jogos musicais como o Yousician, Piano Tiles e Guitar Hero; Tamagochi com a temática já adotada no hospital (com gamificação); e "Desafio do dia", no qual acontece a ação de gravar 3 a 5 segundos pronunciando uma "super sílaba". Estes jogos podem ter sido identificados no Brainwriting pois representam exemplos de jogabilidade de alto engajamento e diversão. Deste modo, são exemplos de jogos que se ajustam ao desafio de fonoaudiologia e ao público infantil. Todas estas ideias têm potencial para ser utilizadas em outras soluções semelhantes para atividades fonoaudiológicas, ou para versões futuras e expansões do jogo enquanto uma plataforma de apoio.

\subsection{Caracterização do Jogo}

Com base nos resultados da oficina, foi produzida a ideia do jogo Fonopets. Na tela inicial do jogo, há um animal que fica feliz quando o usuário faz os exercícios diários e triste quando o usuário não os faz. A adição de sentimentos em expressões do animal busca ser um fator adicional de engajamento, para que a criança sempre deixe o animal feliz. No jogo há um progresso diário (representado por uma barra) associado a este animal, cuja emoção é refletida pelo progresso. A criança também pode selecionar qual animal gosta mais, permitindo um nível de identidade entre usuário-animal.

Também há na tela inicial uma barra de progresso que mostra quantos pontos o usuário precisa obter por dia. Essa meta pode ser customizada pela fonoaudióloga durante as consultas, de forma a adaptar corretamente para diferentes necessidades de tratamento. Ao completar a meta diária, o jogo incentiva o usuário a fazer um desafio: filmar o próprio movimento da boca pronunciando uma sílaba ou palavra difícil, em um vídeo de três a, no máximo, cinco segundos. Esse vídeo ficará armazenado no celular para ser transmitido quando existir uma conexão Wi-Fi. Existe possibilidade para o armazenamento e transmissão de dados por meio de um diretório compartilhado via Google Drive, de modo que a fonoaudióloga possa acessar e averiguar o progresso que ocorreu desde a última consulta. Há um menu para acessar cada modalidade de jogo, representada por um animal diferente.

A escolha por modalidades se deu a partir da necessidade da criança usar o app diariamente, em que dificilmente uma única solução seria capaz de não se tornar repetitiva, previsível ou cansativa com o tempo. Inspirado na ideia do jogo WarioWare, que agrupa dezenas de jogos com mecânica simples, mas que têm alto valor de repetitividade e engajamento, foram propostos, portanto, quatro modalidades diferentes para o Fonopets. Tomando inspiração na temática já desenvolvida com o Hospital, cada modalidade possui um animal diferente como personagem representado, por exemplo: pássaro, coelho, sapo e cobra.

A primeira modalidade é baseada no jogo Flappy Bird no qual um pássaro precisa atravessar diversos canos com diferentes alturas. Os canos se movem horizontalmente com velocidade constante, enquanto o pássaro se move verticalmente, com a força da gravidade. Diferente do jogo original, a mecânica será por meio da voz, não do toque. Por este motivo, para evitar que o jogo se torne complexo, a força da gravidade deve ser reduzida, assim como a velocidade com que os canos se movem.

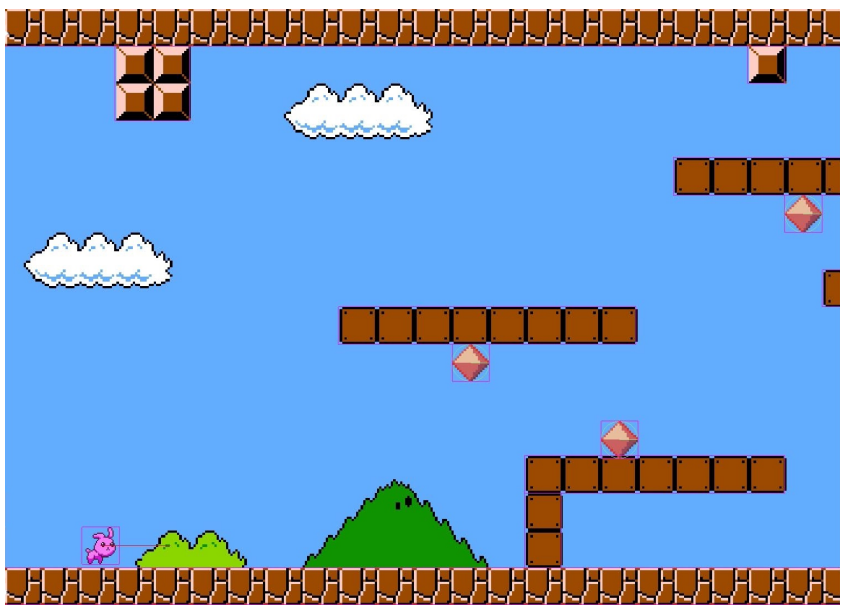

Figura 4: Protótipo funcional da segunda modalidade.

A segunda modalidade é baseada no jogo Super Mario. A proposta é que essa modalidade tenha a voz como forma de controle manipulando o pulo do personagem. No protótipo implementado (Figura 4), não foi permitido ao usuário controlar o movimento horizontal do personagem (que é automático), apenas se a gravidade estará para cima ou para baixo. Além disso, no protótipo foram usados blocos especiais que, ao serem encostados, geram uma situação diferente, como inverter a velocidade ou teleportar o personagem. Em uma implementação com maior número de fases ou níveis, poderia ser utilizada uma mecânica mista, com mais controles, em que o usuário pudesse controlar o movimento horizontal do personagem pelo toque na tela, além do movimento vertical pela voz.

A terceira modalidade proposta é inspirada no jogo Frogger, no qual um sapo tenta atravessar ruas e rios sem ser atropelado pelo trânsito ou se afogar na água. A proposta é que essa modalidade use a voz como a forma de mover o personagem para frente, verticalmente. Como alguns obstáculos (e.g., troncos) estão em constante movimento horizontal, o jogador precisa manter a concentração e jogar precisamente. Essa modalidade, portanto, depende menos da quantidade de vezes em que o usuário pronuncia uma palavra e mais de sua precisão.

A quarta modalidade proposta é inspirada em jogos como Guitar Hero, Piano Tiles e Yousician. O objetivo é que o usuário diga fonemas ou palavras no tempo certo, seguindo indicação visual na tela associada a alguma melodia. Podem existir modos com várias palavras diferentes e cada uma tenha que ser dita na hora certa. Também pode ser explorada a precisão do ritmo da fala.

Os aspectos principais da solução são:

- promover maior afinidade da criança com o jogo, ao selecionar diferentes tipos de avatares;

- permitir ajuste de metas e progressos diários pela fonoaudióloga, de modo a promover engajamento para realização das atividades;

- transmitir vídeos e áudios gravados nos exercícios de forma assíncrona;

- quatro modalidades diferentes de desafios com mecânica simples, mas com valor de repetitividade e engajamento. 
O jogo foi concebido de modo a engajar, além da criança, toda a família ou pessoas próximas a ela. Como há inspirações em jogos conhecidos e populares, essas pessoas também podem participar dos desafios. Isso possibilita que o jogo seja um objeto de partilha de experiências colaborativas e evita que seja exclusivo.

Um protótipo do jogo foi construído e avaliado com usuários, mas a descrição da implementação do jogo e de sua respectiva avaliação não fazem parte do escopo deste artigo, que foca na oficina realizada para entendimento do problema e prospecção de ideias, antes do desenvolvimento de uma solução e do envolvimento direto do público-alvo.

\section{DISCUSSÃO}

A oficina realizada trouxe impactos para o jogo construído: i) definiu o que era essencial ou prioritário em termos de partes interessadas, de valor agregado da solução e de possibilidades dessa solução ir além do óbvio; ii) clarificou que um jogo único não seria capaz de favorecer a resolução do problema, que implicou na ideia de diferentes módulos de jogo para uma mesma solução.

O jogo sério possui um contexto específico e partes interessadas delimitadas como prováveis beneficiárias de um jogo. Estas partes interessadas poderiam não ser identificadas facilmente em um jogo de apenas lazer ou entretenimento, pois esse tipo de jogo possui público-alvo extenso. Isto não acontece em um jogo sério, que tem um conteúdo que quer ser ensinado ou simulado para determinado indivíduo. O Design Socialmente Consciente traz uma visão sistêmica do contexto e dos jogadores que podem influenciar no processo de jogar, desde aqueles que não irão jogar até aqueles que irão jogar diretamente o jogo.

O Quadro de Avaliação possibilita uma visão abrangente sobre o problema de diversas partes interessadas. Seu potencial em relação ao projeto de um jogo é destacar explicitamente que o jogo pode ir além de ser apenas um meio educacional ou de entretenimento, podendo acarretar ou lidar com problemas de diversas ordens na vida de um indivíduo, desde os aspectos informais e sociais, até os aspectos técnicos de infraestrutura e recursos disponíveis.

No Quadro de Prospecção de Valor, o elemento de "como a solução pode melhorar a vida das pessoas" é um aspecto que pode não estar explícito no desenvolvimento tradicional de um jogo. Trazer essa preocupação ou reflexão pelo menos de forma explícita é um elemento crucial para o sucesso do jogo e para promover os resultados esperados: em vez de simplesmente utilizar o conceito de um jogo para apresentar os exercícios de fonoaudiologia, esses exercícios devem ser parte intrínseca e natural, acontecendo como parte integrante do jogo. Embora parte do conhecimento advindo do Quadro possa ser adquirido por outros artefatos, como o Business Model Canvas (e.g., campos de "Proposta de Valor" e "Segmentos de Clientes”) [16], o Quadro é sucinto por apresentar poucos pontos de reflexão, mas abrangente o suficiente ao tocar em aspectos de "dores" das partes interessadas e seus desafios, e os aspectos da solução e suas oportunidades, sendo adequado para uso em oficinas de entendimento do problema e prospecção de ideias.

A Escada Semiótica convidou a pensar na possível solução sob várias perspectivas. Qualquer decisão de design em um degrau da escada implica em modificações em outros degraus, o que possibilita uma visão sistêmica da solução. A escada pode ser fortalecida no contexto de jogos ao, por exemplo, associarmos os degraus aos elementos de jogos de usuário, implementação e universo diegético de um artefato como a E-MUnDi [9]. Essa combinação pode permitir verificar a possível solução em diversos níveis de análise, sobre o contexto do problema, da solução e sobre elementos de um jogo.

A oficina tem uma abordagem que permite verificar os stakeholders do jogo em abrangência, sejam usuários diretos ou indiretos do jogo. Na literatura os stakeholders em sua maioria limitam-se aos possíveis usuários diretos do jogo. Por um lado, estes são considerados como relevantes para definição de estratégias de motivação e de mecânicas [3]. Por outro lado, assim como na oficina, é expressa a necessidade de considerar o público-alvo no projeto de jogos de forma mais sistêmica, por exemplo por uma via participativa e centrada no usuário [1]. Em abordagens da literatura também aponta-se a necessidade de entendimento do domínio do problema e da solução [1], mas sem apontar para isso um método ou artefato específico. Os artefatos utilizados na oficina se mostraram possíveis opções para apoiar a concepção de jogos no entendimento de problema e caracterização da solução. Por fim, a abordagem da oficina tem um diferencial de buscar identificar para os stakeholders o principal valor agregado do jogo, elemento que vem antes e pode auxiliar a definição de estratégias educacionais ou de jogabilidade.

A oficina teve duração de uma manhã (4 horas), mas somente 2 horas destas foram utilizadas na prática de produção de entendimento do problema e de ideias de solução, enquanto o restante do tempo foi utilizado para discussão sobre os artefatos, suas teorias de base, e sobre o contexto real do problema no hospital parceiro. Nesse período de meio dia de trabalho, geramos para um jogo várias ideias potenciais que resultaram da prática de identificar stakeholders em abrangência, verificar o problema e a solução em diferentes níveis de demandas e necessidades, entender os stakeholders como partes interessadas e colocá-los no centro do processo, imaginando uma solução que agregue valor para eles; e gerar ideias diversificadas para serem candidatas a desenvolvimento, prototipação e testes. Essa oficina é ideal para os estágios iniciais de desenvolvimento de uma solução, que pode ser aliada aos modos de desenvolvimento mais tradicionais, divididos em etapas bem definidas, ou aos modos mais ágeis, com etapas iterativas focadas em rápida produção. $\mathrm{O}$ propósito principal deve ser entender o problema em uma perspectiva sociotécnica, antes do desenvolvimento de uma solução e do envolvimento direto do público-alvo.

Esta abordagem de oficina, apesar de produzir um entendimento abrangente e gerar várias possibilidades de ideias de solução para um jogo, também tem limitações e pontos de exploração. Enquanto uma abordagem informada pela teoria da Semiótica Organizacional, a abordagem possui complexidade de entendimento e uso dos conceitos.

Em nossa prática, os envolvidos receberam um treinamento prévio para preencher os artefatos e o doutor com conhecimento sobre IHC e Semiótica Organizacional atuava como mediador em determinados momentos, explicando sobre conceitos, por exemplo. Em um cenário real de construção do jogo, há uma necessidade de aprendizagem anterior ao uso dos artefatos, ou mediação de um especialista sobre os conceitos utilizados. Entretanto, pode se apontar que os artefatos que apresentam conceitos mais complexos são, principalmente, o DPI e a Escada Semiótica. Os demais artefatos possuem preenchimento intuitivo, à medida que trabalham com questões 
próximas de projetistas. Se por um lado todo processo, método ou técnica demandam algum nível de aprendizado e familiarização, por outro, é natural esperar que uma abordagem que pretenda apoiar o design em uma perspectiva sociotécnica tire os participantes de sua zona de conforto e apresente algum nível de dificuldade.

A oficina contribui para o entendimento de problema e prospecção de soluções, ajudando a evitar problemas clássicos no desenvolvimento de soluções que, embora tenham como objetivo promover algum benefício ao seu público-alvo, acabam colocando-o em segundo plano. A oficina promove a discussão, o debate e o exercício de uma perspectiva sociotécnica preocupada com os impactos e resultados esperados com a solução. Uma oficina dessa natureza é essencial não apenas por produzir ideias e evitar problemas, mas por favorecer uma construção de entendimento compartilhado entre os participantes desde o início do processo de design.

\section{CONSIDERAÇÕES FINAIS}

Este artigo apresentou uma oficina de Design Socialmente Consciente, realizada para entender o problema em uma perspectiva sociotécnica e prospectar ideias para um jogo digital que apoie atividades de exercícios de fonoaudiologia. Com a realização desta oficina foi produzido um entendimento colaborativo sobre o domínio do problema e sobre os impactos da solução, como a necessidade das partes interessadas e as oportunidades existentes no domínio.

No desenvolvimento de jogos tradicionais, pode não estar explícita a preocupação social e responsável de um jogo, principalmente dos impactos negativos que este pode causar. A oficina apresentada promoveu uma discussão mais ampla sobre os impactos positivos que devem ser explorados e aspectos negativos que devem ser considerados.

A oficina realizada, além de identificar os stakeholders óbvios da solução, auxiliou a identificar usuários indiretos; a Escada Semiótica auxiliou a considerar aspectos sociotécnicos, desde a parte técnica até a infraestrutura humana; no Quadro de Prospecção de Valor nos aproximamos de uma compreensão mais relacionada a empatia, investigando para o stakeholder central qual poderia ser o valor agregado da solução. No Brainwriting colaborativo, levantamos requisitos e ideias na sua maior diversidade possível. As ideias produzidas não envolviam somente funcionalidades, mas requisitos não funcionais, como qualidade do software.

Os resultados da oficina foram utilizados como insumos para a criação de um protótipo de jogo para a plataforma Android. O jogo já está operável e foi avaliado com diferentes especialistas, com indícios encontrados de engajamento entre usuário-jogo. Os próximos passos da pesquisa envolvem adaptar ou desenvolver uma versão completa do jogo que possa ser experimentada com seu público-alvo e comparada com as outras soluções existentes.

A partir desta oficina e do entendimento sociotécnico derivado podemos indicar uma maior possibilidade de não ficar apenas em soluções óbvias ou automatizadas, considerando o usuário não apenas como um sujeito da tecnologia, mas como seu principal beneficiário. Por exemplo, poderia ter sido desenvolvido uma ideia de jogo que apenas monitorasse a criança. Neste modo de design de jogos por meio da oficina, temos outra perspectiva: o primeiro valor é que o jogo tem que ser divertido e prover um sentimento de progresso nas atividades.

\section{ACKNOWLEDGMENTS}

Agradecemos as valiosas contribuições e participação dos integrantes do laboratório IHC-UFPR. Este artigo é parcialmente apoiado pela Coordenação de Aperfeiçoamento de Pessoal de Nível Superior - Brasil (CAPES) - Código de Financiamento 001.

\section{REFERÊNCIAS}

[1] Vero Vanden Abeele, Bob De Schutter, Luc Geurts, Stef Desmet, Jeroen Wauters, Jelle Husson, Lieven Van den Audenaeren, Frederik Van Broeckhoven, Jan-Henk Annema, and David Geerts. 2011. P-III: A player-centered, iterative, interdisciplinary and integrated framework for serious game design and development. In Foint Conference on Serious Games. Springer, 82-86.

[2] Amigofono. 2019. Amigofono para Pacientes. https://play.google.com/store/ apps/details?id=com.amigofono.app. Online; Acessado em julho de 2019.

[3] Leonard A Annetta. 2010. The "I's" have it: A framework for serious educational game design. Review of General Psychology 14, 2 (2010), 105-113.

[4] Liam Bannon. 2011. Reimagining HCI: toward a more human-centered perspective. interactions 18, 4 (2011), 50-57.

[5] Maria Cecilia C Baranauskas. 2009. Socially aware computing. In Proceedings of International Conference on Engineering and Computer Education, Vol. 6. Claudio da Rocha Brito \& Melany M. Ciampi, 84-88.

[6] Maria Cecília C. Baranauskas. 2015. Sistemas sócio-enativos: investigando novas dimensões no design da interação mediada por tecnologias de informação e comunicação. FAPESP Thematic Project (2015/165280) (2015).

[7] Maria Cecília Calani Baranauskas, Maria Cecília Martins, and José Armando Valente. 2013. Codesign de Redes Digitais: tecnologia e educação a serviço da inclusão social. Penso Editora.

[8] Jose V. da Silva, Vanessa R. M. L. Maike, Luã M. Muriana, Camilla V. L. T. Brennand, Roberto Pereira, Tânia Lima, and Maria Cecília C. Baranauskas. 2019. Explorando Afeto e Sócioenação no Cenário de um Hospital. Technical Report. Universidade Estadual de Campinas, Instituto de Computação. http://www.ic.unicamp.br/ $\sim$ reltech/2019/19-02.pdf

[9] João Victor da Silva Cardoso, Eric Low Schmidt, and Roberto Pereira. 2018. Emundi - um framework conceitual para a análise e concepção de jogos eletrônicos. Anais do $27^{\circ}$ Simpósio Brasileiro de fogos e Entretenimento Digital, 142-151.

[10] Fofuuu - Saúde e Desenvolvimento Infantil. 2019. Fofuuu - Para Pais. https: //play.google.com/store/apps/details?id=com.fofuuu.apps.kids. Online; Acessado em julho de 2019.

[11] Simon Frost and Rachel J McCrindle. 2016. Speech development and therapy using the Kinect. International fournal of Child Health and Human Development 9, 3 (2016), 269-279.

[12] Sylvia Krischke, Susan Weigelt, Ulrich Hoppe, Volker Köllner, Michael Klotz, Ulrich Eysholdt, and Frank Rosanowski. 2005. Quality of life in dysphonic patients. Fournal of Voice 19, 1 (2005), 132-137.

[13] Kecheng Liu. 2000. Semiotics in information systems engineering. Cambridge University Press, New York, NY, USA.

[14] David R Michael and Sandra L Chen. 2005. Serious games: Games that educate, train, and inform. Muska \& Lipman/Premier-Trade.

[15] Jeannie Novak. 2011. Game development essentials: an introduction. Cengage Learning, New York, NY, USA.

[16] Alexander Osterwalder and Yves Pigneur. 2010. Business model generation: a handbook for visionaries, game changers, and challengers. John Wiley \& Sons.

[17] Roberto Pereira and Maria Cecília Calani Baranauskas. 2015. A value-oriented and culturally informed approach to the design of interactive systems. International fournal of Human-Computer Studies 80 (2015), 66-82.

[18] Lara S. G. Piccolo and Roberto Pereira. 2017. Culture-based artefacts to inform ICT design: foundations and practice. AI \& SOCIETY 34, 3 (2017), 437-453.

[19] Cláudia F Pollonio and Regina MA de C Freire. 2008. O brincar na clínica fonoaudiológica. Distúrbios da Comunicação 20, 2 (2008), 267-278.

[20] Ovidiu Andrei Schipor, Stefan Gheorghe Pentiuc, and Maria Doina Schipor. 2012. Improving computer based speech therapy using a fuzzy expert system. Computing and Informatics 29, 2 (2012), 303-318.

[21] Ronald K Stamper. 2001. Organisational semiotics: Informatics without the computer? In Information, organisation and technology. Springer, 115-171.

[22] Arthur B VanGundy. 1984. Brain writing for new product ideas: an alternative to brainstorming. Journal of Consumer Marketing 1, 2 (1984), 67-74.

[23] Wim Westera, RJ Nadolski, Hans GK Hummel, and Iwan GJH Wopereis. 2008. Serious games for higher education: a framework for reducing design complexity. fournal of Computer Assisted Learning 24, 5 (2008), 420-432.

[24] Amri Yusoff, Richard Crowder, Lester Gilbert, and Gary Wills. 2009. A conceptual framework for serious games. In 2009 Ninth IEEE International Conference on Advanced Learning Technologies. IEEE, 21-23. 